\title{
The Behaviour of the Chromosomes in Pinus and Thuja.
}

BY

\author{
I. M. LEWIS, \\ University of Indiana.
}

\section{With Plates XXIX and XXX.}

ATHOUGH the behaviour of the chromosomes in the two divisions A attending spore formation in the higher seed plants has been a favourite subject for research, the majority of investigators have confined their attention to certain favourable forms of the Angiosperms, and only a few extensive investigations have been made in the Gymnosperm group. Among these, the work of Miss Ferguson ('04) for Pinus is doubtless the most comprehensive. The results obtained by that writer differ so much from conditions that are known to exist in other forms that their confirmation seems much to be desired. Certain other questions have arisen since the time at which the genus Pinus was investigated which render desirable a study of some members of this group. Among these questions may be mentioned the manner of conjugation of the maternal and paternal chromosomes to form the bivalents and the possibility of recognizing prochromosomes in the resting nucleus.

The forms investigated were Pinus strobus, $P$. austriaca, $P$. Laricio, and Thija occidentalis. Figures are shown from the different species, but when differences exist such differences have been noted. Frequent references are made to the work of Miss Ferguson ('04) which is, in a large measure, confirmed by my own results.

\section{Methods.}

The methods used were such as are employed in any piece of modern plant cytology. The cones were fixed as soon after their removal from the tree as was possible. The fixing fluid used was the chrom-osmic-acetic fluid of the formula proposed by Mottier ('97). The staminate cones were cut into small pieces, and the hard points shaved off with a razor, thus rendering the sectioning of the pieces more satisfactory. In some cases the individual sporophylls were removed and fixed. This causes considerable difficulty in sectioning, but the fixation in material so treated was found to

[Annals of Botany, Vo1. XXII. No. LXXXVIII. October, 1908.]

O o 
be perfect. The time of fixation was from twenty-four to thirty-six hours, and the material was then washed in running water twelve hours, passed through the grades of alcohol, chloroform, and paraffin, and embedded in paraffin. Sections were prepared varying in thickness from five to twenty microns. Bleaching was effected by placing the slides for a few minutes in an alcoholic solution of hydrogen peroxide. The stains used were the triple stain and Haidenhaine's iron-alum haematoxylin. For the stage of the resting nucleus and mitotic figures the triple stain is far superior, but for other stages of the prophase the iron-alum seems to give better results. Full sets of preparations were made using both stains.

\section{The Phenomena of the Prophase.}

The present trend of thought regarding reduction has directed attention especially to the prophase of the first division, with especial emphasis upon the resting nucleus and the stage of synapsis. At the close of the last division in the archesporial cells of both Pimus and Thuja the nucleus soon passes over into what is universally regarded as the resting stage. The nuclear content consists at this time of irregular chromatic lumps connected by delicate, anastomosing linin threads which stand out with great clearness and beauty in sections well differentiated with the triple stain. Concerning the question of whether two substances are to be distinguished here, nothing new can be added, but there is no doubt that the staining reaction of the chromomeres and the so-called linin is quite distinct. There seems to be a tendency on the part of the chromatin to become quite finely dissected, but there are always some bodies which remain quite large (Pl. XXIX, Fig. I). The number of these lumps is always quite in excess of the number typical of the somatic chromosomes of the sporophyte generation and does not approximate to this number by subsequent fusions. Mottier ('07) has shown for Lilium that the extent of dissection in the chromatic masses may be quite variable in closely connected cells of the same antherloculus. In this genus it seems that in some of the cells the bodies in question become finely broken up and separated along the linin threads, while in others they remain more closely intact. He has raised the question as to what extent this difference in appearance may be caused by the reagents, as it seems quite probable that the action of osmic acid might exert some such influence on the chromatic substances, but no very definite results have as yet been obtained. This writer observed and figured nuclei exhibiting both of these conditions as they passed on into the synaptic condition, and they seem to behave in precisely the same manner, no matter which condition prevails in the resting nucleus. He concludes, therefore, from a long comparative study of the forms investigated, that the number and size of the chromatic lumps is a matter of minor importance. Miyake ('05) made a comparative study of a long list of plants, and he finds that 
the lumps are quite variable in respect to both size and number. In Lilium he states that the number is often greater than that of the somatic chromosomes, and does not reach this number by subsequent fusions. In other genera he has, however, reported conditions which are more in harmony with the idea of prochromosomes. Overton ('05) states that in Thalictrum purpurascens, Helleborus foetidus, and Campanula grandis, the chromosomes of the last somatic division remain visible in the nucleus of the spore-mother-cell as rather large lumps, which resemble the somatic chromosomes, and which always coincide with them in number. He speaks of these accordingly as 'prochromosomes'. These lumps he finds to be generally arranged in pairs. The linin strands connecting them are always arranged parallel, and some of the chromatin not contained in the bodies is distributed along the strands. Previous to the synaptic phase, it often happens that the prochromosomes become broken up and distributed along the threads of linin, and thus there are formed two fine continuous threads of linin studded throughout with chromatin. In this condition synapsis is reached.

In neither Pinus nor Thija, as stated above, does the number of chromatic bodies ever approach the number of somatic chromosomes. These bodies are always quite numerous, but they do not appear to become so finely granular and dissected as seems to be the case in Lilium. There is also no tendency toward an approximation in pairs. The linin threads are not arranged parallel to each other, but rather anastomose in all directions. The chromatin is often distributed for some little distance along these strands, but it is confined principally to the chromosomes themselves. It often happens that two or more bodies are found lying together in close proximity, but no good reason is seen for interpreting this as an indication that they are preparing for fusion in pairs. Equally clear is it that an occasional linin thread follows for a short distance the same course as one lying near it (Fig. I), but, judging from the extreme rarity with which this phenomenon occurs in these genera, it is my opinion that this is merely a matter of chance and has no significance whatever.

Allen, Guignard, Berghs, Cardiff, and others have reported conditions for many genera of plants in which the linin threads become arranged parallel to each other, and then by the reticulation and distribution of the chromatin along these threads two fine spirems are formed prior to synapsis. During the synaptic phase these spirems fuse more or less completely into one. In both Pimus and Thuja the first indication that the synaptic condition is approaching is the withdrawal of the nuclear network toward one side of the cavity. There is no evident change at this time in the content either in structure or staining reaction. The chromomeres retain approximately the same size as before, and the linin still retains its characteristic staining reaction. The net becomes somewhat contracted towards the side 
of the cavity, but a few chromomeres may be seen lingering behind. Linin threads pass out toward the nuclear membrane, and the whole gives one the impression that the content has simply contracted. There is at this time no structure which can be regarded as a continuous spirem (Fig. 2). The contraction continues, the elements retaining the same structure and staining reactions, and in such nuclei there can be no doubt of the manner in which the chromatic content approaches synapsis. There is no indication of a pairing or conjugation of the chromomeres or of the linin threads, but rather a contracting of an irregular reticulum of single threads studded throughout with single chromomeres (Fig. 3). Before the greatest degree of contraction is reached the chromomeres give evidence of dissolution into the smaller granules of which they are composed. These granules are apparently drawn out along the linin strands, numerous cross strands are drawn in, and the reticulum seems to be passing over into a skein or spirem (Fig. 4). The content stains more uniformly now than prior to this time. Following this condition the contraction becomes so dense that even in the best differentiated preparations it is impossible to observe clearly what takes place (Fig. 5). One can only observe the phenomena leading up to this condition and the recovery from it.

Synapsis has been, and still is, variously interpreted by different workers. That it is a perfectly normal step in the process of reduction seems now to be generally agreed, Schaffner ('07) being perhaps the only investigator who still maintains the view once prevalent that this condition is an artifact. It must be admitted that the nucleus is at this time the seat of great activity, that the nuclear cavity is enlarging to its final size, and that conditions are therefore favourable for faulty fixation. But when one considers the differences between the structure of the nuclear content as it passes into this condition and as it recovers from it, together with the uniformity with which it occurs during the reduction division, and the fact that it has been frequently observed in living cells, the last objection seems to fall.

The term synapsis has come to be used in a different sense from that in which it was first employed by Moore ('95). This writer was the first to call attention to the fact that the unilateral massing of the chromatic content of the nucleus is a normal step in mitosis. At that time, although all other investigators held this condition to be purely an artifact, Moore expressed the belief that whatever synapsis might eventually turn out to be, 'it is evidently a cellular metamorphosis of profoundly fundamental character,' and, judged in the light of present interpretations, he could not have made a better supposition. The term synapsis was used by Moore to denote a definite stage or phase of mitosis, the meaning of which was not known and only in a vague way conjectured. Its application to this phase was soon adopted, and all investigators, whether recognizing the stage as normal 
or as an artifact, employed this term to denote it. As the meaning of the synaptic phase became clearer it was generally recognized as being concerned with the uniting of somatic univalents in pairs to form the heterotype bivalents. Accordingly the term came to be used by certain observers, as suggested by McClung ('02), to mean 'the fusion of single chromosomes into multiple ones, usually of a bivalent value'. It has been suggested therefore that a new term, synizesis, be adopted to signify the stage of mitosis first denominated as synapsis, and that the latter term be used to denote the conjugation of the maternal and paternal chromosomes. To this there seems to be certain well-founded and serious objections, chief among which may be mentioned the fact that the exact meaning and significance of this stage of mitosis has not been definitely and finally determined. The term has been used through all the literature of the past ten years to denote that very definite stage of mitosis which has been universally observed and which has as yet been only partially explained. The term should be retained with its original meaning whatever significance may be attached to the stage of mitosis it represents. If the meaning of synapsis should be found to be, as is strongly probable, the conjugating of univalent chromosomes, then we would have two terms which signify the same thing and the one would be superfluous, a condition recently reported by Miss King ('07) for Bufo.

The tightly contracted stage of synapsis persists frequently for several days, depending upon growth conditions, and in any sporangium the cells reach this stage quite uniformly. Cardiff ('06) has attempted to explain the one-sided position of the chromatin mass as due to gravity, but in neither of the two genera investigated does this explanation hold. In cells lying adjacent to each other, the contraction has been always toward the periphery, but without any apparent relation to the stimulus of gravity. From the balled-up mass threads eventually begin to disentangle themselves and pass out into the cavity. These threads unless cut by the knife are always in the form of loops (Fig. 6).

The spirem thread is now seen to exhibit a very uniform structure. The chromomeres are much more uniform in size than at the beginning of the synaptic phase, and they are embedded in the more lightly staining linin. The thread at this time is seen to show indications of longitudinal fission. This first becomes evident from a careful examination of the chromomeres themselves. In sections well differentiated with the iron-alum stain the chromomeres are clearly seen to occur quite regularly in pairs, although there is an occasional unpaired one (Fig. 6). Allen suggests that the appearance of double chromomeres at this time has been confused, because the chromomeres are not always differentially stained, and, being larger than the linin cord in which they are embedded, the swellings which project over the side have been mistaken for the double rows of chromo- 
meres. However, this objection does not hold true for these genera. In sections in which the parts of the spirem are well stained differentially, the chromomeres are clearly observed in pairs, and this pairing is interpreted as due to a longitudinal fission (Figs. 6,7 ). The formation of the spirem from the reticulum of the resting nucleus together with its contractions and recovery from synapsis and subsequent fission agrees closely with that given by Miss Ferguson ('04).

In a short time the nuclear thread has completely disentangled itself and wound quite evenly throughout the entire cavity (Fig. 8). This figure is drawn from a section twelve microns thick. The free ends are seen to occur on the cut surfaces, and a study of this stage in preparations cut thick enough to include the entire nucleus has convinced me that there is present at this time an endless spirem. The spirem is quite jagged or granular in appearance, but when one observes closely the chromomeres the double nature is always revealed.

The halves of the spirem now tend to diverge somewhat at intervals, but only in occasional nuclei do they ever become widely separated. The fission of the spirem was preceded by longitudinal fission of the chromomeres, and this was evident at the time the skein loosened up from the synaptic ball. The longitudinal fission never becomes decidedly pronounced in either genus, in fact it might readily be overlooked entirely. Fig. 9 is drawn from the same loculus as Fig. I2. The majority of nuclei exhibit the structure of Fig. 9. These figures are typical of the spirem at this time. It has begun to stain much more uniformly than at the stages immediately following synapsis and the ragged nature is beginning to disappear. In place of such a structure a smooth homogeneous cord is formed (Figs. IO, II). When one considers the extreme rareness with which nuclei are met with that reveal a divergence of the halves of the spirem, one is strongly inclined to disregard this as a normal step in the process of chromosome development. As the spirem shortens and thickens somewhat it becomes generally quite evenly distributed, and almost all evidence of longitudinal fission is lost.

While these changes have been taking place in the chromatin, certain changes have gone on in the cell itself, which seem to be typical of this stage of mitosis and which may serve in a general way as an index of such stages. The cells during the resting period of the nucleus are packed together closely and are always polygonal in shape. The nucleus occupies a position near the central part of the cell. This position of the nucleus does not persist long, and gradually it tends to move toward one end of the cell. The cells begin to show signs of dissolution from each other by the time the synaptic mass has reached its state of greatest contraction, and when the nucleus has fully recovered the cells have rounded up and the tissue connexion has been lost. 
That synapsis has to do with the rearrangement of the chromatin seems probable, but just what takes place is a matter of pure theory. Farmer ('07) suggests that there probably occurs in synapsis an organization of the homologous chromomeres into chromosomes ; that the homologous chromosomes so derived from the maternal and paternal chromatin respectively then unite to form the heterotype bivalents. The conjugation of the somatics is conceived as being effected end to end. Each bivalent consists, therefore, of homologous maternal and paternal primordia. The question naturally arises here as to just what significance is to be attached to the term homologous; for it becomes at once evident that, if the chromosomes, so conjugating during synapsis, are exact homologues, there is no basis for the transmission of paternal differences, unless we modify our conception by the idea of dominance. If these members of the bivalents are exact homologues, then the first division is equational and not differential, although reducing.

The extent to which affinity of the primordia will cause them to unite seems to underlie all theory of chromosome formation. For certainly the theory of the individuality of chromosomes, the formation of differentials, and the conjugation of somatics during synapsis, is based on the affinity of the units of which they are composed. That this affinity is based on chemical and physical laws seems quite reasonable, but one must not lose sight of the fact that these activities are taking place in living protoplasm.

Mottier ('07) suggests that during synapsis pangens of like affinity become united into homologous chromomeres, and that these chromomeres then come together to form chromosomes. This idea, carried to its extreme form, must arrive at the conclusion that certain chromosomes are composed always of the same primordia, for if homologous units unite persistently they must form bodies which represent always the same characters, and in this sense they will be individuals. Farmer ('07) maintains that 'the chromosome must be indifferent as to the chromomeres which enter into its formation'. He states, however, that at meiosis the pairing takes place in such a way that like joins with like to form the pseudochromosomes. It becomes evident that if this condition has become fixed the chromosomes represent groups of homologous characters united together by mutual affinity. But, on the other hand, if the chromosomes are formed out of the chromomeres by the organizing power of the cell, as maintained by some writers, then a chromosome represents only an accidental accumulation of primordia and not a permanent entity.

The behaviour of the nucleolus has been so thoroughly discussed in all research on the behaviour of chromatin that it would seem useless to enter into a further discussion of the matter here. I have not, however, been able to recognize such a direct relationship between the chromatin and nucleolus as described by Cardiff ('06) for Acer, but am disposed to agree with the view 
already quite well established that the nucleolus is concerned in some way with the elaboration of the chromatin.

My study of the nuclei as they approach and recover from synapsis has convinced me that the difference of interpretation prevailing among cytologists at present in regard to the conjugation of the spirems is due to a confusion of the stages. Cardiff's ('06), Figs. 8, 9, 10, 12, 43, 54, 63 are, judging from my own experience with mitotic division, drawn from postsynaptic nuclei, although they are much more diagrammatic than anything I have encountered in any cells yet studied.

\section{Formation of the Chromosomes and THEIR Distribution} TO THE DAUGHTER NUCLEI.

The manner in which the chromosomes are formed from the spirem presents the greatest difficulty of any step in the entire process of mitosis in these genera. The origin of the spirem and its behaviour subsequent to synapsis seems to preclude the possibility that the chromosomes represent pieces of the spirem in which the longitudinal fission has again become evident, although such a view was formerly held by those investigators who believed in a double longitudinal fission. This view is also held by those who interpret the fission of the prophase as a conjugation of maternal and paternal spirems side by side. Miss Ferguson ('04) maintained that the spirem, which is formed as described above, segments into pieces which equal the number of somatic chromosomes typical of the species. These segments then unite in such a way as to give rise to a sort of reticulum, which finally segments again to form the bivalent chromosomes. Each bivalent consists therefore of two somatics which have become united before final cross-segmentation. The chromosomes are arranged in the post-synaptic nucleus end to end, but the pieces which form the parts of any one bivalent are not necessarily adjacent to each other until after the first transverse segmentation. This view harmonizes somewhat incompletely with that of Farmer and Moore, Mottier, Schaffner, Juel, and others.

The spirem of Pimus and Thuja, as indicated above, becomes a regular homogeneous band in which only the slightest evidence of the longitudinal split remains. It is wound evenly throughout the cavity and consequently thrown into a number of loops (Figs. IO, II). That the number of loops corresponds to the number of bivalent chromosomes cannot be stated definitely, although there may be some such relation. The spirem thickens very considerably and signs of cross-segmentation become quite evident. In some nuclei the number of loops is now almost identical with the reduced number of chromosomes (Fig. I4). This figure is drawn from Thuja. The nucleus is shown almost entire and the loops are quite as regular as any yet observed for this or any other genus. It is also quite evident here that the sides of the loops are double in certain places, although usually the double 
nature is concealed. From a study of the chromosomes just after crosssegmentation of the spirem and before the segments have thickened to their final form it becomes evident that two pieces have become in some way approximated to form the bivalents. That these two members are the sides of the loops there seems little doubt. There are, however, many nuclei in which such a looping of the spirem with such diagrammatical regularity cannot be observed. In such nuclei the looping is far less regular. The spirem often has not become entirely regular, but has retained to a considerable extent its lumpy nature and the longitudinal split has not entirely disappeared (Fig. 13). The spirem consists of short loops, but there are often stretches of considerable length in which there seems to be no tendency to form loops. These pieces often reach almost across the nuclear cavity (Figs. I3, I6). That the chromatin content is being drawn out of the parts of the cord and deposited in other is often quite evident (Fig. I5). This often presents the appearance of dark, deeply staining parts connected by thin strands, the whole appearing like a reticulum (Fig. I5). It seems that the spirem breaks up and pieces are brought together and fuse. There is no such massing of the spirem in this condition to a central aggregation as is often apparent in other nuclei. It seems quite likely that the spirem completes its cross-segmentation without further change and gives rise to the bivalent chromosomes. This method, while varying somewhat from the condition in which regular loops are formed, is seen to admit of the same interpretation, namely, that two pieces previously arranged 'tandem' in the spirem become approximated to form a chromosome.

The chromosomes formed as shown in Figs. 17, I8, I9 now enter upon the period of shortening and thickening. Some of the pieces are variously oriented toward each other, and it becomes evident that many of the forms observed at this time consist of the two sides of a loop which have become bent together and applied closely, while others are completely broken apart or the line of demarcation is quite distinct. The pieces are often twisted over each other at this time, but, as shortening and thickening takes place, they seem to straighten somewhat and appear more like straight pieces lying alongside each other, or as links or rings. The $\mathrm{Y}$ and $\mathrm{X}$ forms and the figure eight are also to be found.

There is nothing in the spirem of either Pinus or Thuja to indicate the relation which the somatic chromosomes bear to each other. Miss King ('07) has shown that in Bufo certain chromosomes have the typical ring-form which has been commonly observed in all studies of the heterotypical chromosomes, while others are of a dumb-bell shape. In that form the spirem from which the chromosomes are formed is never found to be split longitudinally, and thus all possibility of their origin as demanded by the popular theory of conjugation side by side is precluded. Miss King ('07, Figs. 28-3I) shows very clearly that the chromosomes are arranged 'tandem ' 
in the spirem and that they may either give rise to rings by looping on themselves (Fig. 31) or dumb-bells by cross-segmentation without looping (Fig. 28); the cardinal points of this being, that no conjugation of spirems takes place before synapsis, that the chromosomes are united end to end to form the bivalents, and no longitudinal split is observed. A similar method of conjugation of chromosomes has been given by Strasburger ('04) for Galtonia and by Mottier ('07) for Tradescantia.

The chromosomes are now located mainly near the nuclear membrane which has up to this time retained its characteristic appearance. The chromosomes are connected more or less by thin delicate strands which often reach out to the nuclear membrane or even to the cytoplasm. The nuclear membrane now begins to fade out and spindle fibres crowd into the cavity. At this time the segments have shortened almost to their final form, although there is yet considerable difference in their relative sizes. The segments in Thuja become relatively much shorter and thicker than in Pimus, and accordingly the stages following spindle formation are much more difficult to follow than in Pinus. The orientation of the chromosomes into the equatorial plate now takes place. This occurs quite rapidly and the chromosomes become arranged almost in a single plane. This is quite strikingly true of Thuja. The structure and relation of segments is not so apparent at this time, but a careful examination reveals all of the forms observed in the prophase. The chromosomes are closely crowded together and some are in a plane slightly above or below the rest. There is no indication that the segments have begun longitudinal fission as yet (Fig. 20). The stage of the spindle plate lasts some time in Thuja, as the division goes on comparatively slowly in this form. The spore-mother-cells undergo this division about the first week in February. Entire sporangia have been observed in which every cell exhibited the chromosomes in the plate of the spindle. Such cones brought into the laboratory and placed in a warm place finish the division in a few hours.

The manner of attachment of the spindle fibres, as well as the behaviour of the chromosomes during the metaphase and anaphase, was found to be in general harmony with the well-known accounts of Strasburger ('00) and Mottier ('03). Miss Ferguson ('04) states that the spindle fibres are never attached at the free ends of the segments, but invariably at some point along the fused part, but this does not appear to me to be the case. The chromosomes are usually arranged tangential to the spindle and sheaves of fibres are attached to the segments either at the free ends or at the point of adherence of the two segments. A few of the chromosomes stand radially to the spindle.

The separation of the daughter segments now takes place. Two wellknown theories are still held as to the manner in which the separation is effected. Miss Ferguson ('04) maintains that the sister segments are not 
separated in this mitosis, but that the original longitudinal fission again becomes evident and the daughter segments separate along this line of fission, thus one half of each somatic passes to each daughter nucleus and this mitosis effects an equational division. After a careful study of such stages, as shown in Figs. 21, 22, 2.3, the opposite view has been adopted, namely, that the segments separate in such a way that one of the halves of the bivalent passes entire to each daughter nucleus, thus bringing about a reducing division. Fig. 21 shows the beginning of metakanesis; the segments shown are not the longitudinal halves of the daughter segments, for, as will be shown in later stages, longitudinal fission has not yet taken place. The chromosome in the middle was a ring-shaped one, while those to the right and left were composed of two straight pieces which may have been oriented in any of the ways mentioned above. The ends are drawn together as they converge toward the poles and in many cases they are so close together that they may appear fused. This is, however, more apparent than real. The segments at this time are quite thick, but appear slightly more drawn out than when in the spindle plate before metakanesis begins.

After the segments entirely separate from each other and move toward the poles, each is seen to split longitudinally. The appearance of this fission is often very much delayed, but it takes place quite generally, as shown in Fig. 22. It may be readily seen here that the segments begin their fission at the equatorial end and separate along the entire length. The equatorial ends diverge somewhat and the characteristic $\mathrm{V}, \mathrm{U}$, or double $\mathrm{V}$ is formed. The second chromosome from the left represents a ring-shaped form in which longitudinal fission has taken place, giving rise to the double $\mathrm{U}$, while that lying next to it may be due to a long rod-shaped one which has bent on itself at the place to which the spindle fibres were attached. Sometimes it happens that one of the granddaughter segments slips past its mate, the chromosome at the left, but they more than often remain together. Frequently their polar ends seem to be fused, but this does not appear to be the rule. In Fig. 23, the granddaughter chromosomes are shown just as they arrive at the poles. Longitudinal fission is now complete. The segments have not yet contracted and show the same long-drawn-out appearance which is typical of this stage of mitosis in Pimus. It is evident here that longitudinal fission has been complete, although the ends of some of the segments are very closely applied to each other and often seem fused. The granddaughter segments now approach very close to each other, and it becomes difficult to trace the individual members. A more or less complete spirem is formed, and about the same time the nuclear membrane is laid down. This spirem which has been formed by end-to-end fusion of the segments soon gives signs of dissolution, and, with the growth of the daughter nucleus to its full size, the spirem has entirely lost its identity and a com- 
plete resting nucleus is formed (Fig. 24). The chromatin now exists in the state of rather large irregular lumps connected by linin threads, the whole presenting an appearance not strikingly different from the resting nucleus of the spore-mother-cell of the first mitosis (Fig. 25).

The question quite naturally arises at this point as to the possibility of the complete re-formation of the granddaughter segments during the homotypic mitosis ; also as to the meaning of the longitudinal fission of the prophase and the relation which it bears, if any, to the fission which occurs during the anaphase. It has been quite generally assumed that the fission which occurs in the chromosomes as they pass to the poles is but the reappearance of that which takes place during the prophase, but it will be remembered that this former fission had apparently entirely disappeared at the time of the final shortening and thickening of the chromosomes, so that only a theoretical basis exists for such a supposition. Those investigators who believe in the morphological continuity of chromosomes are not willing to admit that a complete resting stage is reached between the two mitoses, but nothing can be clearer than that such is the case in Pimus, as was pointed out by Miss Ferguson and confirmed in this work for both Pimus and Thija.

\section{The Homotype Mitosis.}

The nucleus remains in this condition but a short time when there are once more signs of the formation of a spirem. Many of the delicate anastomosing strands are drawn in and the chromatin becomes evenly distributed along the connecting threads, in which case a rather broad spirem is formed. This spirem is never entirely complete, as there are always many folds and occasional cross branches (Fig. 26). It is always, however, a single cord. Miss Ferguson states that this spirem during its final segmentation into chromosomes forms in loops across the spindle fibres, and that as cross-segmentation takes place the loops undergo longitudinal fission, and that accordingly two U-shaped segments are formed from each loop. These daughter segments then separate completely and form the chromosomes of the homotype mitosis. I have examined many nuclei in all stages of this mitosis in both Pinus and Thuja with this one point constantly in mind, but have never been able to find any evidence at all convincing that such a condition occurs in either genus. The spirem is formed as a single cord and so it always remains. The chromosomes are formed by cross-segmentation of the spirem (Fig. 27). The shape of the chromosomes vary considerably. They are generally, however, rather long rods, either straight or hooked at the end, or bent in the middle. The compound curve is occasionally met (Figs. 27, 28).

Before cross-segmentation has taken place the nuclear membrane has disappeared, and spindle fibres crowd into the cavity (Fig. 26). The spirem then segments transversely into the chromosomes. These chromosomes 
do not seem to occur so regularly in pairs as described for many other plants, but are scattered throughout the cavity. Orientation into the spindle plate soon follows (Fig. 28). The segments are generally placed tangential to the spindle and do not all occur in the same plane (Fig. 29). It is often difficult to determine the two segments which make up the respective chromosome. When the chromosomes finally become arranged in the plate of the spindle they are very much crowded together, and it is very difficult to follow all of the segments. It is quite certain, however, that from their manner of segmentation and orientation no such longitudinal fission occurs as that described by Miss Ferguson. The chromosomes often reach across the equatorial plate, so that it becomes difficult to determine toward which pole some of the segments will eventually pass. The fibres are attached to the ends in the great majority of cases, but in a few instances they may be attached near the middle. In a number of cases observed a few of the segments were seen to stand radially to the long axis of the spindle. The segments are entirely free from each other and each now constitutes a chromosome. At the beginning of metakinesis a much-tangled appearance is often presented and some of the segments seem to be standing radially to the axis of the spindle. This is due to the fact that some of the segments which pass to a given pole lie on the opposite side of the nuclear plate and are bent somewhat by the pull which seems to be exerted by the fibres. As the segments separate and pass to the poles, all of the forms observed in the prophase are met with. The segments seem to straighten as they move apart. This is always true of the forms which are attached to the ends. As the segments pass toward the poles the equatorial ends of neighbouring chromosomes diverge, while the polar ends come close together, thus forming the characteristic V. This figure is therefore due to two different chromosomes, which are so closely applied to each other as to appear fused. Some of the long rods which were attached to the spindle near the middle form the $U$ shape, but the straight rods forming V's are much the commoner form (Figs. 32,33 ). After the segments reach the pole they shorten and become closely applied to each other and their identity is soon lost.

There is nothing, apart from purely theoretical reasons, in either of these genera, to indicate that the segments which occur in the homotype mitosis are the same as the ones which were present during the anaphase of the first. As already stated above, the chromosomes of the first mitosis lose their identity completely before the spirem of the second is formed. The loss of identity is as complete as is that which occurs in the resting nucleus preceding the heterotype division. What basis exists then for asserting that the homotype chromosomes are identical with the granddaughter segments of the first mitosis? This centres again on the question of the individuality of the chromosomes. If the chromosomes are not capable of a complete 
re-formation as maintained by Farmer ('07), Mottier ('03), Foot and Strobell ('07) and others, then it becomes at once evident that the segments are formed anew and that the material primordia, pangens, or chromosomes are again shuffled and grouped into new combinations. Such a view leaves meaningless the longitudinal fission of the spirem during the prophase of the first mitosis, as well as that of the chromosomes during the anaphase. These two fissions have generally been regarded as one and the same, and as being concerned with an equational division which is completed during the homotype mitosis. But this supposition demands the morphological continuity of chromosomes, an hypothesis concerning which the gravest doubts have been raised by the most competent investigators. The homotype division is not therefore, according to this view, analogous to a somatic division, the equational part of which took place during the preceding mitosis, but is in fact what it appears to be-also a qualitative division. The first division is qualitative and reductional.

\section{General Considerations.}

A more uniform interpretation prevails among botanists to-day concerning the phenomena of fertilization and reduction than at any time in the history of these most perplexing of all questions. That fecundation effects an approximate doubling of the number of chromosomes, half of which are furnished by each of the fusing gamete-nuclei, has long been known. Equally clear has been the knowledge that this number must be reduced at some time previous to the formation of the next succeeding generation of germ-cells. The method by which this reduction takes place has been a very difficult problem, and, although no solution has yet been offered which satisfies all of the phenomena observed by different investigators, there is a growing tendency toward a common view of the essential nature of the process as a whole.

At present the view which was formerly held by many of the best investigators, that the reduction is accomplished in the resting nucleus, and after two longitudinal fissions of the spirem the chromosomes are distributed essentially in the same way as in somatic divisions, has been almost, if not quite abandoned. This view not only failed to harmonize with the observed facts of the behaviour of the chromatin, but also failed to furnish a suitable basis for theoretical considerations based on the known facts of heredity. It has, accordingly, been gradually superseded by a growing belief, which is now almost universal, that a true reducing division takes place as proposed by Weismann several years ago, although it is quite generally agreed that the reduction occurs in the first rather than the second mitosis. This change of conception was brought about largely by a more careful study of the early prophase of the first mitosis, as well as by a more general accept- 
ance of the theory of the individuality of the chromosomes; for, if the chromosomes are to be regarded as individuals, it is clear that reduction can take place only when one of the two tetrad or maturation divisions is transverse.

The belief in a true reducing division is not new, but its general adoption as a true process of meiotic division is comparatively recent. Probably the greatest stimulus to research along this line was exerted by the re-discovery of the Mendelian principle of the segregation of characters in certain inbred hybrid forms.

As long ago as 1884 , Heuser asserted that there occurs in Tradescantia virginica a transverse division of the chromosomes in the first mitosis, and that this mitosis effects, therefore, a qualitative division. Korschelt ('95) reported similar conditions in the annelid Ophryotrocha puerilis, but neither of these investigators succeeded in convincing subsequent observers of the accuracy of his work, and it was passed unheeded. It was not until experimental investigators had re-established the Mendelian principle of character segregation in hybrids that botanists began with renewed energy the search for a reducing and a qualitative mitosis.

Too much credit cannot be given to the plant breeders for the valuable contributions they have made in the form of statistical reports of the outward manifestations of hereditary characters in many species of plants. This work, while furnishing valuable criteria for the cytologists, has done more to dispel the idea that fecundation consists in the chemical union of the two fusing gamete-nuclei than could ever have been accomplished by the student of cytology alone. The students of experimental research on heredity have been driven to assume the material primordia of characters which the cytologists have been able to demonstrate as existing in the germ nuclei, and thus the two working from directly opposite sources have reached the same conclusion, a coincidence which must be regarded as of the greatest significance. There seems no longer any doubt that there exist in each gamete-nucleus certain material primordia which are in some way responsible in the determination of the characters of the resulting organism. That these primordia, or determinants, are definite chemical compounds seems quite probable, although nothing explicit can be offered along this line at the present time. All the experimental work of the past argues strongly against the idea that these primordia fuse at fecundation in such a way as to give rise to an entirely new hereditary substance. On the contrary investigation seems to bear out the view that the primordia are merely mixed in a mechanical way, but without chemical union. Whether these material primordia of characters be regarded as the chromosomes themselves, as has been generally the case, or as the smaller particles of which they are composed, as suggested by Weismann and variously modified by De Vries, Strasburger, Mottier, Farmer, and others, it seems quite 
generally agreed that they are separate, distinct entities which persist in their individuality from cell generation to generation.

Although Rabl ('85) was the first to attribute to the chromosomes the property of individuality, Boveri ('08) first formulated the hypothesis which has had such far-reaching influence on all subsequent work in cytology. While Boveri's hypothesis was not accepted without reserve by all investigators, it has been quite generally adhered to, and it is only just recently that it has again been brought seriously into question. Recent research has caused a growing belief that too much speculation has been based on the theory of the individuality of the chromosomes.

All work of the past which has been done in support of the hypothesis has endeavoured to show that the chromosomes are capable of a complete re-formation after having first entirely lost their identity in the resting nucleus. The researches of Herla ('93), Haecker ('95), Moenkhaus ('04), Ruckert ('04), Zoga ('95) and others furnish us with abundant evidence that the maternal and paternal chromatin remain distinct from each other for at least several divisions in the developing embryo. Ruckert has also shown that the chromatin of the germinal vesicle appears in two distinct groups, and he suggests as possible that these groups may represent the maternal and paternal elements which have remained distinct throughout the entire life of the organism down to the formation of the egg. It has been shown for Pinus by Miss Ferguson ('04), Blackman ('98), Chamberlain ('04), and others that the gamete-nuclei do not unite at fecundation and that the chromosomes of the first cleavage division of the egg appear in two groups. Blackman ('04) and others have shown that the two nuclei in the Uridineae do not fuse for many generations after their association in the same cell, in fact not until the close of the life cycle-the meiotic phase. Moenkhaus ('04) showed that the chromosomes actually remain distinct in a certain hybrid fish until the third division of the embryo. Probably the strongest argument in favour of the persistence of the chromosomes from generation to generation as distinct morphological identities is to be found in the report of Rosenberg ('04) for Drosera hybrids. This writer has shown that in the hybrid sporophyte produced by crossing Drosera rotundifolia with $D$. longifolia, which have respectively ten and twenty chromosomes, the chromosome number is thirty as would be expected. At the time of the next succeeding reduction division, however, the number is not fifteen bivalents as would be found ordinarily after normal fecundation, but ten bivalents and ten univalents. Since the chromosomes of the two original species differ in both form and size, it is possible to recognize the chromosomes of the maternal and paternal ancestry. It is found, therefore, that the ten bivalents are formed of one from each ancestry respectively, and that the ten univalents are the ten from the one ancestry which did not find mates in the other group. This evidence seems to point conclusively 
to the fact that the chromosomes have retained throughout the life of the organism down to spore-formation their individuality, and have simply become associated in pairs during meiosis.

Less certain evidence is that derived by Farmer ('07) for hybrid ferns. In Polypodium Schneideri, the result of a cross between $P$. aureus and $P$. elegantissumus, the chromosome number at meiosis is not a mean between that of the two species from which it was derived, but is considerably larger. There are in this case also several unpaired members. The large number of chromosomes of this hybrid, as well as the original species from which it was derived, renders the results less convincing than that of the Drosera hybrid.

Another piece of evidence which has had great influence on this favourite hypothesis is the presence in certain insects of differential chromosomes which are so different from all others that they may be followed readily from one division to another. It is, in fact, to this phenomenon more than to any other that we are largely indebted for our present view of synapsis and reduction, first suggested by Montgomery ('01) and later developed by Sutton and Boveri.

Wilson ('05) concludes from a study of these differentials that the chromosomes are 'definite, well characterized entities which show the most marked individual characteristics of behaviour, which in some manner persist from one cell generation to another without loss of their specific character, and which unite in synapsis and are distributed in the next ensuing maturation division in a perfectly definite manner'. This writer regards, therefore, the question of the individuality of the bodies in question as definitely settled. He considers the problems of cytology to be 'problems of the comparative morphology and physiology of the chromosomes with the ultimate aim of attempting their specific correlation with the phenomena of heredity and development'. Wilson himself, working on this hypothesis, has developed his well-known theory of sex determination. But in the plant world, although differences have often been noted in respect to both size and shape of chromosomes, no such differentials occur as are found in the cases cited above. Cardiff ('06) has suggested that it is highly probable that one chromosome in Acer is structurally different from the others, but he does not offer any speculation as to its significance. Likewise Gates ('07) ventures the assertion that a differential occurs in Oenothera. Full confidence cannot be placed in this work, however, until it is more certainly reported and definitely confirmed for many genera of plants, a condition which it seems safe to predict will never be realized. In almost any spore-mother-cell the chromosomes differ in form and size, but that this difference is constant enough to warrant any definite conclusions concerning their correlation with heredity and development does not seem probable. 
Briefly then the theory of the individuality of the chromosomes finds its strongest support in the behaviour of the chromosomes in hybrid forms, coupled with the presence of the peculiar differentials and the observed methods of separation and distribution during the two divisions attending reduction. Conclusive as the evidence in favour of the hypothesis seems to be, the recent contributions of Foot and Strobell ('07), Farmer ('07), and of Mottier ('07), have strongly questioned its validity. These writers have pointed out certain objections to the hypothesis, chief among which may be mentioned the difference in the number of chromosomes typical of a species, and the number of characters into which the species may be analysed which behave as distinct allelomorphs. This objection was also recognized by Weismann, but has been given new meaning through the definite proof afforded by recent experimental work. It has been urged that each chromosome may be regarded as a material primordium for a group of correlated characters, and this is to a certain extent borne out by experimental evidence. For example, Mendel ('65) found that in Pisum a grey, grey-brown, or leather-brown colour of the seed-coat always occurs in connexion with violet-red blossoms and reddish spots in the leaf-axils. This correlation of all the characters in groups becomes lost, however, when the entire number and relative independence of the allelomorphs is considered. It seems necessary to associate some smaller unit with the occurence of unit characters.

Brauer ('93) thought that the chromomere rather than the chromosome should be regarded as the element which retains its individuality from cell generation to generation. This theory has recently received new recognition from Mottier ('07) and later from Farmer ('07). Mottier has suggested that the smallest visible chromatin granule be taken as the unit which retains its individuality. These units he designates as pangens. The next higher aggregation of granules is the chromomere. Farmer ('07) regards the chromomere as the distinct entity and material primordium of the unit characters. He considers the chromosome as made up of a number of organized chromomeres, but the same chromomeres do not necessarily always go together to form a chromosome. There is, therefore, according to this view no persistence of the chromosomes from cell generation to generation as distinct individuals, but rather they are formed anew at each succeeding division out of the individual chromomeres which have retained their identity.

Much importance has always been attached to the fact that the chromosomes are constant in number, and much speculation has been based on the number of chromosomes in the germ-cells of certain species. Farmer ('07) has shown that in certain ferns chromosome numbers are present which deviate greatly from the number typical of the species from which they have sprung. He concludes that this number must have arisen 
through a rearrangement of the substance of which the chromosomes are formed, and regards this as proof of the variable nature of these bodies. The same writer concludes that the 'number and form of the chromosomes typical of any species is evidence rather of the organizing function of the cell as a whole than of the independent nature of the chromosomes themselves'.

In connexion with this theory of the individuality of the chromomeres and variability of the chromosomes another set of phenomena must be taken into consideration, namely, the origin of the chromosomes from the male and female ancestry respectively, and the possibility of their recognition in the resting nucleus. As implied above it has been quite generally accepted that the two sets of chromosomes remain distinct throughout the growth period in the life of the organism and unite only at the time of meiosis. This supposition has been attacked by Mottier ('07) and also by Foot and Strobell ('07). Mottier ('07) sees no reason for regarding the chromatin as remaining in such a complete state of segregation, since there is but one known genus (Pinus) in which the maternal and paternal chromosomes do not entirely lose their identity at the time of fecundation. He also points out the fact that any interchange or pairing of pangens may as readily take place at this time as during meiosis. There is no time it seems in the entire process which is so well fitted for distribution and rearrangement as the stage during which the chromatin exists in the finely divided state connected by delicate anastomosing linin threads.

Foot and Strobell ('07) have shown for Anasa tristis that the morphological identity of the chromosomes is entirely lost during the rest period of the first spermatocyte, but that among the eleven chromosomes which emerge from this resting nucleus there are three which differ so markedly from the others that they are readily distinguished from the early prophase to the telophase of the second spindle. These forms are the so-called eccentric chromosome, the microchromosome, and a large cross-shaped one. These authors conclude, however, that this is not an indication of the morphological continuity of these forms, for it is argued that if during the growth period the chromosomes pass over into the form of a chromatin reticulum, skein, or granules, there is no ground for asserting that the chromosomes have retained intact their morphological continuity. It is also maintained that no basis exists in fact for asserting that the paired bivalents are two of the somatics of the maternal and paternal ancestry which have remained together. It is urged that the chromosomes which make up the heterotype bivalents are formed anew out of the material of the chromosomes of the preceding generation, a view which harmonizes with that set forth by Mottier ('07) and by Farmer ('07).

It is a fact worthy of note that Foot and Strobell have based their conclusions on the same data from which Montgomery, Stevens, Wilson, 
and others have derived their well-known theories of synapsis and reduction which are so directly opposed. In Anasa tristis much importance has been attached to the fact that in certain of the microchromosomes there is a considerable variation in size from those demonstrated in any other of their preparations (Foot and Strobell, '07, Plate II, Photo 3). In this cell the other chromosomes are somewhat smaller than usual. It is pointed out that if these two parts of the bivalents be interpreted as having been derived respectively from the maternal and paternal ancestry, then 'it becomes necessary to accept the theory that not only two individuals can show exactly the same marked variations in the same chromosome, but that these two rare cases should unite, a condition which seems unlikely'. According to this argument it also becomes necessary that the eleven daughter bivalents of a group should be as constant as the equality in size of two daughter bivalents, and this is shown not to be the case in Anasa. These authors also point out the fact that if such differences in size be due to parental differences, then we should rarely find two daughter bivalents exactly alike, but that this equality of daughter bivalents is a conspicuous fact. Briefly, then, the evidence derived from a study of the differential chromosomes of this form is not in harmony with the wellknown hypothesis as it has been variously developed by different investigators.

By attributing the property of individuality to the finer units of which the chromosomes are composed, we do not by any means preclude the possibility that some chromosomes may from cell generation to generation retain to a certain extent their morphological continuity. It cannot be doubted that in cells in which divisions are taking place rapidly, the chromosomes of the preceding generation can often be almost certainly recognized as irregular lumps which have not become so finely dissected as may happen when divisions are further removed. My opinion is, however, that too much importance has been assigned to this phenomenon by recent observers, for, if the chromosomes are seen to be without that persistent individuality which has been attributed to them, then, the socalled prochromosomes are seen to lose the significance with which they have been regarded.

Investigators have sought at different times to prove that it is possible under certain conditions to recognize the chromosomes of previous generations in the resting nucleus of somatic and germ-mother-cells. Rabl ('85) believed that he could recognize traces of the chromosomes in the resting nucleus, and he regarded the reticulum of such nuclei as having arisen by the giving off of anastomosing branches by the chromosomes, thus causing an apparent loss of identity. At the next division, however, the chromatic substance flows back through predetermined paths, and occupies the same position as before the loss of identity. He concludes, therefore, that the 
chromosomes persist in the reticulum of the resting nucleus in the form of bodies with projecting processes.

The majority of investigators since the time of Rabl, while contending for the truth of the general hypothesis set forth, have failed to recognize anything comparable with the chromosomes in resting nuclei. Recently, however, Rosenberg ('04) and Overton ('05) have asserted that in certain genera it is possible to recognize in the resting stage of the nucleus a number of chromatic lumps which is equivalent to the number of somatic chromosomes typical of the species. For these lumps Overton ('04) has suggested the name prochromosomes. As already stated above it is not disputed that the chromosomes may for a time persist as rather large irregular lumps, but it seems quite probable that such appearances are due rather to growth conditions than that they represent a condition which has any great significance from the standpoint of heredity. For is it not true that, in at least the great majority of forms of both plant and animal so far thoroughly investigated, all vestiges of the structure of the chromosomes of the preceding generations are lost ? The term prochromosomes, as applied to the chromatic lumps of the resting nucleus, is open to certain objections which are well founded. In all of the forms which Overton himself cites, it appears that the identity of these bodies is completely lost before final chromosome development takes place, so that it cannot be definitely stated that these bodies represent structures which are even approximately the same as the chromosomes of this division, as the name would imply.

In the case of Podophyllum, Overton ('05) says: 'Doch die Hauptsache ist, dass auch hier, gerade so wie bei den andern Pflanzen, Linin und Chromatinstruktur parallel zu liegen kommen'. And this, if it be true, relegates the entire speculation concerning prochromosomes to a position of minor importance.

This statement brings us also to a consideration regarding the origin of chromosomes from the spirem, concerning which there is a wider diversity of opinion than for any other stage of mitosis. It is maintained by one group of investigators, among whom Strasburger, Guignard, Berghs, Allen, Overton, and others are prominent, that the chromatin of the resting nucleus exists in a state of complete segregation, and that previous to synapsis, the maternal and paternal each arranges itself into a continuous spirem. These two spirems, lying close to each other, become arranged parallel throughout, approach very close together, and apparently fuse side by side. This fusion takes place during the synaptic phase. Following synapsis the spirems again separate to a greater or less degree, and segment transversely to form the bivalent chromosomes. Each part of a bivalent is therefore derived purely from the maternal or paternal ancestry. The other view which opposes this conception, and which has been supported by Farmer and Moore, Mottier, Schaffner, Juel, and others, denies the presence of two 
spirems previous to synapsis, and asserts that the synaptic phase does not consist in the uniting of somatic chromosomes side by side. This view maintains that the chromomeres and the linin threads connecting them never become arranged in parallel rows, and that the chromatic content of the nucleus approaches the synaptic condition rather in the form of a reticulum of single chromomeres connected by single strands of linin. This chromatin reticulum becomes converted during synapsis into an endless spirem, which undergoes longitudinal fission shortly after it is formed, and then segments transversely into the chromosomes. The chromosomes consist of two pieces of the spirem which have either come together after cross-segmentation or were not disassociated, but remained together at the time of segmentation. These pieces become variously oriented toward each other, and so give rise to the heterotype forms typical of this mitosis, a condition which harmonizes perfectly with the observed facts in both Pinus and Thuja.

It will be seen, therefore, that these two views agree perfectly as to the nature of the bivalent chromosomes, but differ widely as to their manner of origin from the resting nucleus. It seems then that the questions of the origin and ultimate destiny of chromosomes cannot be regarded as finally and definitely settled. In this connexion one must not forget to take into account that, in dealing with a phenomenon of such wide occurrence as that of mitotic division, it is strongly probable that the process will be found to be uniform in regard to all of its essentials, although differing in minor details, else how shall we explain its significance?

\section{The Idioplasmic Theory of Heredity.}

In speaking of the chromomeres as the bearers of hereditary characters, it is, of course, implied that these bodies are responsible only by their influence on the less stable cytoplasm. No attempt will be made at this time to enter into a discussion of the various ways in which the idioplasmic theory, first proposed by Nagelei, has been developed. In some form or other it has held the centre of thought among students of heredity for the past thirty years. That the idioplasm, which is identified by all investigators with the chromatin, constitutes the entire mechanism of heredity has not been accepted by all investigators, and recent work is causing a growing belief that the cytoplasm of the egg at least is fundamentally concerned with the transmission of characters.

In its extreme form the idioplasmic theory assumes that every organism may be analysed into a certain definite number of unit characters, and that in the cells of the organism a number of material primordia may be found which correspond with such units. It is of course needless to say that such a condition has not been shown to exist, although it is known that many characters behave as distinct units. "It is known that a definite kind of 
protoplasm derived from the parents tends to run through a specific cycle of changes, during which it transforms itself into an individual like the one of which it once formed a part,' but whether these changes are dominated by any one part of this protoplasm more than any other is still questioned by a few investigators. All writers recognize the fact that the transmission of hereditary characters is, from the physiological point of view, but the recurrence in successive generations of like forms of metabolism. It is not clear, however, to just what these like forms of metabolism are due. It has been suggested by Fick that every species is characterized by a protoplasm which differs from that of every other. There is, according to this view, a species or individual protoplasm which is handed on unchanged from generation to generation. The differentiation always takes place in such a way that the resulting individual resembles the original of which it was once a part.

If it be true, as has generally been asserted by all students of biology, that the nucleus is the formative centre of the cell, that all processes of constructive metabolism are possible only through the nucleus, then it seems likewise evident that the same body may best be conceived of as responsible for the distinctive changes of metabolism which are manifested in the recurrence of definite characters, such as form, shape, and colour. So conceived, the idioplasmic theory is seen to rest on the assumption that the cytoplasm acting as the substratum of heredity is moulded and rendered specific by the idioplasmic characters of the nucleus. This relation which exists between cytoplasm and the nucleus must be regarded as taking place in accordance with definite chemical or molecular laws, always giving rise to the peculiar protoplasm characteristic of the species or of the individual.

This theory does not deny the fact that the egg-cytoplasm fixes the type of development, or that the cytoplasm is a factor in the transmission of hereditary characters, but maintains that the action of the cytoplasm, whatever it may be, has been determined by the idioplasm. If such a view be accepted, the question arises as to whether the units of the idioplasm are characterized by different activities, or whether they merely act as part of the homogeneous substance. As already implied above, the weight of evidence seems to show that there are permanent elements of the idioplasm which are distinct in structure and function. Whether these material determinants differ in their chemical or molecular composition is not known, but it seems that on this basis only can we conceive their true relation to be the transmission of hereditary characters. The students of cytology working hand in hand with the plant and animal breeders have established many of the fundamentals of heredity. It remains to be seen how much clearer the biological chemist will be able to render the conception. 


\section{SUMMARY.}

I. The chromatin of the resting nucleus exists in the form of rather large granular lumps connected by delicate anastomosing strands of linin. The number of such lumps is always greatly in excess of the number of somatic chromosomes typical of the species. There is therefore no evidence to be found here in favour of the idea of prochromosomes.

2. The nuclear content approaches the synaptic condition while still in the form of a reticulum. No spirem is formed previous to synapsis.

3. The term synapsis should be used to denote the definite stage of contraction which is observed to occur always in spore-mother-cells and which is universally recognized as a normal phase in the process of meiosis.

4. Synapsis does not affect the conjugation in pairs of the somatic chromosomes of the maternal and paternal ancestry respectively arranged side by side.

5. As the chromatin thread recovers from synapsis, it is frequently seen to reveal a double nature and this is interpreted as due to longitudinal fission. Since this double nature is never prominent and eventually almost entirely disappears, it is not considered of paramount importance in the final development of the chromosomes.

6. The spirem becomes somewhat regular and forms loops in some cases, although the number of loops is not always the same as the number of bivalent chromosomes. Some of the pieces become approximated after cross-segmentation. The spirem often presents an extremely ragged reticulate structure just before cross-segmentation.

7. The bivalent chromosomes separate during metakanesis, one member passes entire to each daughter nucleus and thus affects a qualitative division. The retreating chromosomes are seen to split longitudinally as they approach the poles. It may be questioned whether this split bears a relation to the split of the early prophase, since that fission had seemed to entirely disappear.

8. The chromosomes of the first mitosis completely lose their identity in the daughter nuclei, which pass into a complete resting stage and thus all speculations as to their continuity in the following homotypic division is purely theoretical, having no basis whatever in fact.

9. The spirem of the second division is formed singly and never undergoes longitudinal fission as suggested by Miss Ferguson for the genus Pinus. The chromosomes formed from this spirem are rods, either straight, hooked at the ends, or bent in the middle.

Io. The chromomere and not the chromosome is regarded as the idioplasmic unit which, due to its action on the unstable cytoplasm, is responsible for the appearance of characters. 
II. The second division is probably qualitative, since the chromosomes are not conceived of as being capable of complete rehabilitation and it seems reasonable that the material entities become rearranged during the rest period.

I am indebted to Prof. D. M. Mottier for kind criticism and helpful advice during the progress of this work.

\section{BLoomington, Indiana, March 25, 1908.}

\section{LITERATURE CITED.}

Allen, C. E. ('05): Nuclear Division in the Pollen Mother-Cells of Lilium canadense. Ann. Bot., xix, pp. $189-258,1905$.

Brauer, A. ('93): Zur Kentniss der Spermatogenese von Ascaris megalocephala. Arch. Mik. Anat., xxiv, p. I53, I 893 .

Cardiff, I. D. ('06): A Study of Synapsis and Reduction. Bull. Torrey Club, xxiii, pp. 27I-306, I906.

Chamberlain, C. J. ('99): Oogenesis in Pinus Lavicio. Bot. Gaz., xxvii, p. 268, i 899.

Conklin, Edwin G. ('08): The Mechanism of Heredity. Science, xxxvii, No. 68r, pp. 89-99, igo8.

FArmer, J. B. and Moore, J. E. S. ('05): On the Maiotic Phase (reduction division) in Animals and Plants. Quart. Journal Mic. Sci., xlviii, pp. 489-556, 1905 .

Farmer, J. B. and Shove, Dorothy ('05): On the Structure and Development of the Somatic and Heterotype Chromosomes in Tradescantia virginica. Quart. Journ. Mic. Sci., xlviii, p. 559.

Farmer, J. B. ('07): The Structural Constituents of the Nucleus. Proc. Roy. Soc., London, Series, B, vol. lxxix B, p. 534, I907.

Farmer, J. B. and Digby, L. ('07): Studies in Apospory and Spogamy in Ferns. Ann. Bot., xxi, pp. I6I-99, 1907.

Foot, K. and Strobell, E. C. ('05) : Prophase and Metaphase of the First Maturation Spindle of Allolobophoro foetida. Am. Journ. Anat., iv, pp. 199-243, 1905 .

('07): A Study of Chromosomes in the Spermatogenesis of Anasa tristis. Am. Journ. Anat., vii, pp. 279-316, I907.

Ferguson, M. C. ('04): Contributions to the Knowledge of the Life History of Pinus with special reference to Sporogenesis, the Development of the Gametophytes and Fertilization. Proc. Washington Acad. Sci., vi, p. I, I904.

Fick, R. ('05): Betrachtungen über die Chromosomen, ihre Individualität, Reduction und Vererbung. Arch. Anat. Phys., 1905.

GrÉGOIRE, V. ('05): Les cinèses de maturation dans les deux Règnes: Revue critique de la littérature. La Cellule, xxix, pp. $22 \mathrm{I}-376,1905$.

('06): La structure de l'élément chromosomique au repos et en division dans les cellules végétales. La Cellule, xxiii, pp. 3I I-53, 1906.

Herla, V. ('93): Étude des variation de la mitose chez l'Ascaride megalocephala. Anat. Ann., xiii, 1893 .

King, Hellen Dean ('07) : Spermatogenesis of Bufo lentiginosus. Am. Journ. Anat., vii, pp. 345, $38 \mathrm{I}, 1907$.

Miyake, K. ('05): Über Reductionsteilung in den Pollenmutterzellen einiger Monokotylen. Jahrb. wiss. Bot., xlii, p. 83,1905 . 
Moenkhaus, W. J. ('04): The Development of the Hybrids between Fundulus heteroclitus and Menidia notata with especial reference to the Behaviour of the Maternal and Paternal Chromatin. Am. Journ. Anat., iii, p. 29, I904.

Mottier, D. M. ('97) : Beiträge zur Kenntniss der Kerntheilung in den Pollenmutterzellen einiger Dikotylen and Monokotylen. Jahrb. wiss. Bot., xxx, pp. 169-204, 1897. ('03): The Behaviour of the Chromosomes in the Spore Mother-Cells of Higher Plants and Embryosac Mother-Cells. Bot. Gaz., xxxv, pp. 250-82, 1903. ('07): The Development of the Heterotype Chromosomes in Pollen Mother-Cells. Ann. Bot., xxi, pp. 309, 34خ, 1907.

Overton, J. B. ('05) : Über Reductionsteilung in den Pollenmutterzellen einiger Dikotylen. Jahrb. wiss. Bot., xlii, pp. I 2 I $-53,1905$.

Rosenberg, O. ('04) : Über die Individualität der Chromosomen im Pflanzenreich. Flora, xciii, pp. ${ }^{2} 5^{\mathrm{I}-9}, \mathrm{I} 904$.

('04): Das Verhalten der Chromosomen in einer hybriden Pflanze. Ber. Deutsch. Bot. Ges., xxi, p. 110, 1904. xxii, p. 47,1904 .

Schaffner, J. H. ('97): The Division of the Microspore Nucleus (of Lilium philadelphicum). Bot. Gaz., xxiii, pp. 430-52, 1897 .

('06): Chromosome Reduction in the Microsporocytes of Lilium tigrimum. Bot. Gaz., xli, pp. 184-90, 1906.

('07): Synapsis and Synizesis. The Ohio Naturalist, vii, pp. 4I-8, 1907 .

Strasburger, E. and Mot'tier, D. M. ('97) : Ủber den zweiten Theilungsschritt in Pollenmutterzellen. Ber. Deutsch. Bot. Gesellsch., xv, p. $3^{27}, 1897$.

Sttrasburger, E. ('95): Karyokinetische Probleme. Jahrb. wiss. Bot., xxviii, p. I 5 I, 1895.

('04): Über Reductionsteilung. Sitzber. Kön.-Preuss. Akad. Wiss., xviii, pp. $587-61_{4}, 1904$.

1905.

Sutton, W. S. ('03): The Chromosomes in Heredity. Biol. Bull., iv, p. 231, 1903.

Wilson, E. B. ('05a): Studies on Chromosomes. I. The Behaviour of the Idiochromosomes in Hemiptera. Journ. Exp. Zool., ii, p. 37 1, 1905.

('05b): II. The Paired Michromosomes, Idiochromosomes and Heterotype Chromosomes in Hemiptera. Journ. Exp. Zool., ii, p. $507,1905$.

\section{EXPLANATION OF FIGURES IN PLATES XXIX AND XXX}

\section{Illustrating Mr. Lewis's Paper on the Chromosomes in Pinus and Thuja.}

All figures were drawn from sections with the aid of a camera lucida and with a Lietz apochromatic $2 \mathrm{~mm}$. objective, $1 \cdot 30$ apert. Figs. $8, \mathrm{I}_{3}, \mathrm{I} 4,16,18$ with compens. oc. 18 ; all others with compens. oc. I 2 .

Fig. I. Pollen mother-cell of Pinus Strobus prior to synapsis. The chromatin is disposed throughout the cavity in the form of rather large lumps. No indication of pairing of the chromomeres or the linin threads. The number of chromomeres exceeds the number of somatic chromosomes of the species.

Fig. 2. A cell from the same anther locuius. The nuclear network is beginning the contraction which indicates that the synaptic phase is approaching. No indications of a spirem are evident. The chromomeres show no disposition to unite in pairs. Two nucleoli are present.

Fig. 3. The nuclear content is becoming more densely contracted. The chromomeres are beginning to appear as if their material was being spun out along the linin strands connecting them. The content is still a reticulum. 
Fig. 4. A cell from the same loculus as above. Many of the linin strands have been drawn in. The chromomeres have become somewhat evenly distributed along the linin strands and an incomplete spirem is present. Some of the chromomeres still show clearly at this time. No indication of fusion or conjugation of chromomeres or threads. The cells are still in tissue connexion.

Fig. 5. Pimus austriaca. Complete synapsis. The cell has rounded up and the nuclear content is in the tightly contracted condition. Nothing intelligible can be seen at this time.

Fig. 6. From the same loculus as Fig. 5. The synaptic mass is beginning to loosen. Loops project out from the dense mass into the cavity. The chromomeres have assumed a striking uniformity in size and form. The thread is clearly double and the chromomeres occur quite uniformly in pairs.

Fig. 7. Tangential view, same stage as Fig. 6. The double nature of the thread is evident but the parts have not separated from each other.

Fig. 8. Pollen mother-cell of Thuja. A slightly later stage than Figs. 6, 7. The spirem bas become quite evenly distributed throughout the cavity. Its double nature is quite evident, and in a few places the halves tend to separate slightly from each other.

Fig. 9. Pinus austriaca. A complete nucleus is shown. No free ends appear, and it is certain that a continuous spirem exists at this time. The daughter halves of the spirem have not separated.

Fig. Io. Same stage from Thuja.

Fig. II. Slightly later stage. Pinus austriaca. The spirem has contracted somewhat, becoming slightly thicker and more regular. It is distributed quite evenly throughout the cavity, and no signs are evident of a second contraction. This is the stage of the evenly distributed 'hollow spirem' of some writers.

Fig. I2. Pinus austriaca. Tangential view of nucleus. The spirem shows quite clearly its double nature. The sister halves have separated from each other at certain points. This nucleus represents an extreme condition that is met in only occasional cells.

Fig. 13. A later stage from Thuja. The spirem occurs quite regularly in folds or locps. It is more lumpy at this time than is typical of Pinus.

Fig. I4. Thuja. The spirem has become arranged here in a very regular series of loops. Some of the loops are broken at the outer end. There is a dense mass at the inner ends of the loops. Such regular stages are not typical and are met only rarely.

Fig. 15. Thuja. The spirem has given way to a quite ragged reticulum. This stage is frequently met in both genera.

Fig. 16. Thuja. Cross-segmentation of the spirem. Some of the pieces are quite long and are variously oriented toward each other.

Fig. I7. Pinus austriaca. Segments shortening and thickening not yet complete.

Fig. I8. Same of Thuja. The nuclear membrane has disappeared, and the cytoplasm is becoming somewhat fibrillar. There is at this time no evidences remaining of the early longitudinal fission.

Fig. 19. Same for Thuja.

Fig. 20. Mature spindle.

Fig. 21. Metakanesis. The members of the bivalent chromosomes are still attached at the ends and the longitudinal fission is not yet apparent.

Fig. 22. Anaphase in Pinus Strolus. The retreating chromosomes are undergoing longitudinal fission as they pass to the poles. Straight rods, V's, double U's, and rods bent at the end result.

Fig. 23. Pinus Strobus. The granddaughter segments have arrived at the poles. Some of the pieces are quite long drawn out. They are not closely oppressed at this time.

Fig. 24. Daughter nuclei. The chromosomes have almost completely lost their identity.

Fig. 25. Complete resting nucleus formed at the close of the first division. Pinus Strobus.

Fig. 26. Spirem of the second division. The spirem is much branched and irregular. It shows no signs of a double nature. The nuclear membrane has already disappeared and spindle fibres have crowded into the cavity.

Fig. 27. Pinus Laricio. The spirem has undergone cross-segmentation into the univalent chromosomes. The segments are rods either straight, hooked at the end, or bent in the middle. The spindle is not formed completely before cross-segmentation takes place, and the spirem does not undergo longitudinal fission.

Fig. 28. Orientation of the chromosomes into the spindle plate.

Fig. 29. The chromosomes are being brought into the plate of the spindle. 
$55^{6}$ Lewis.-The Behaviour of Chromosomes in Pinus and Thuja.

Fig. 3o. The complete spindle plate. The chromosomes are much tangled, and do not all lie in the same plane.

Fig. 3I. Metakanesis. The various shaped chromosomes may be seen at this time.

Fig. 32. Anaphase. The chromosomes are seen to be either straight rods, hooks, or U's. The $\mathrm{V}$ is due to two straight rods which have more or less completely fused at the ends.

Fig. 33. Anaphase. The segments show the same as the preceding figures.

Figs. 27, 28, 29-33 are taken from Pinus Laricio. 
Arnats of Botany,
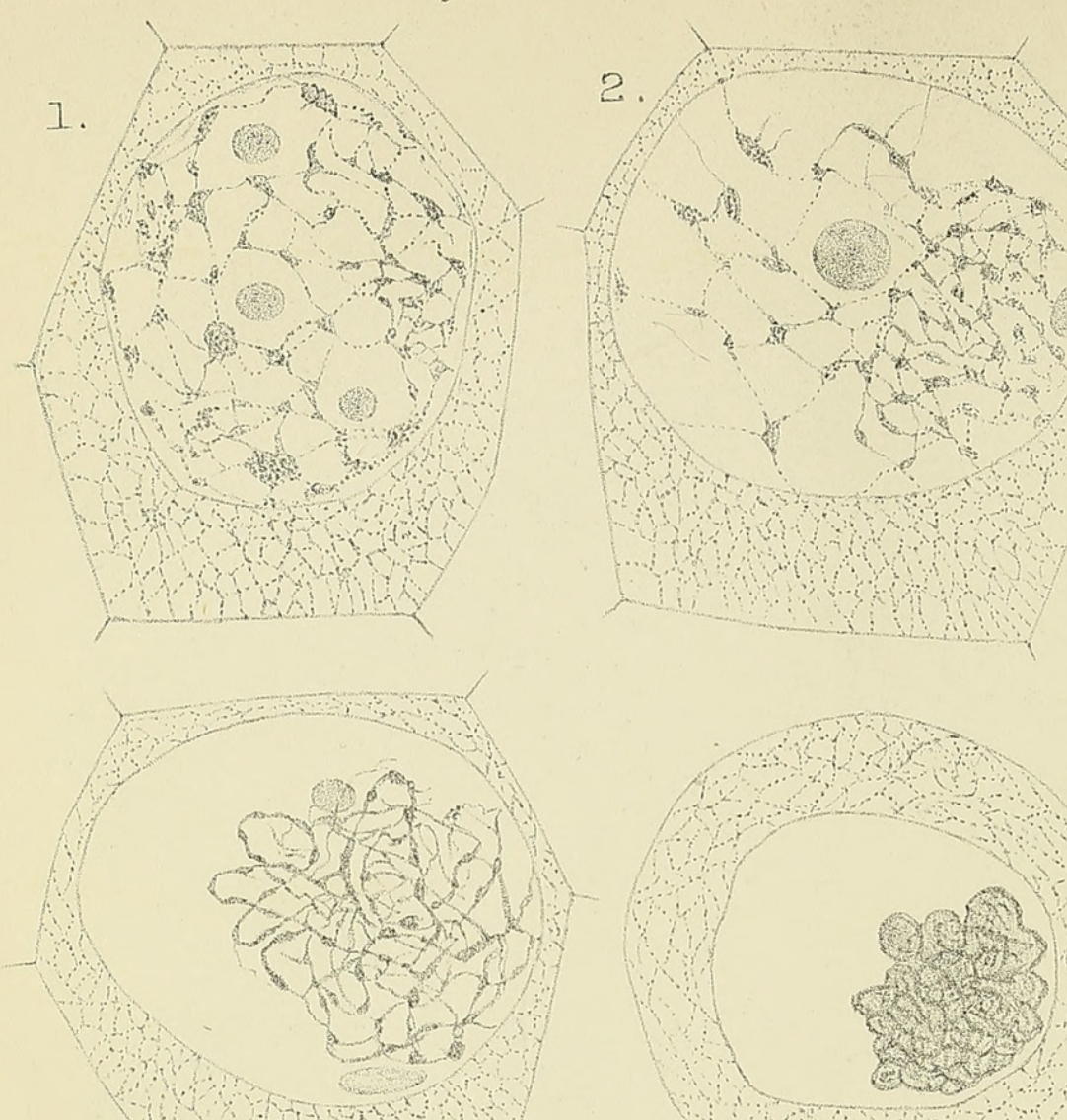

4

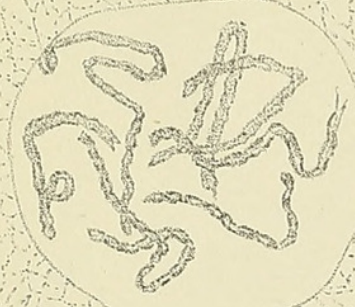

7.

8.

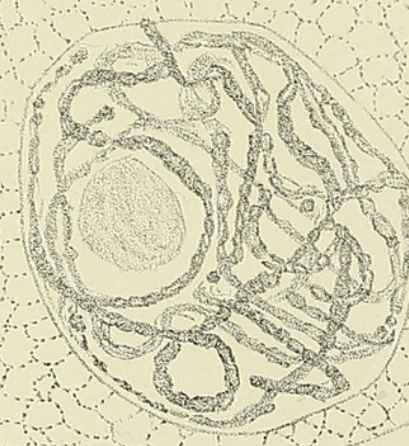

5.

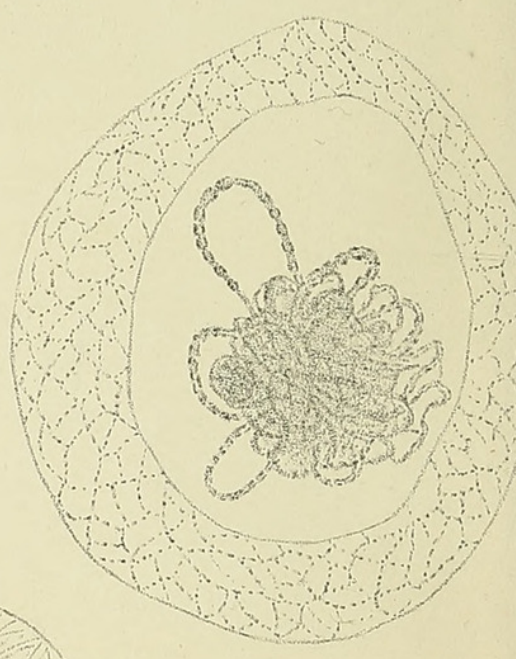

6.

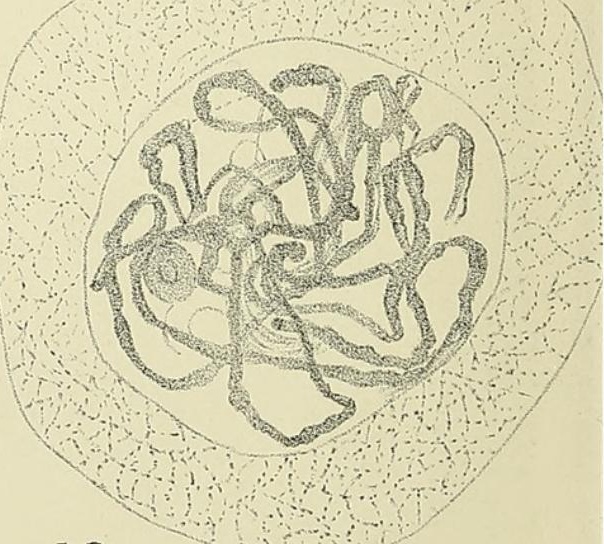

10. 


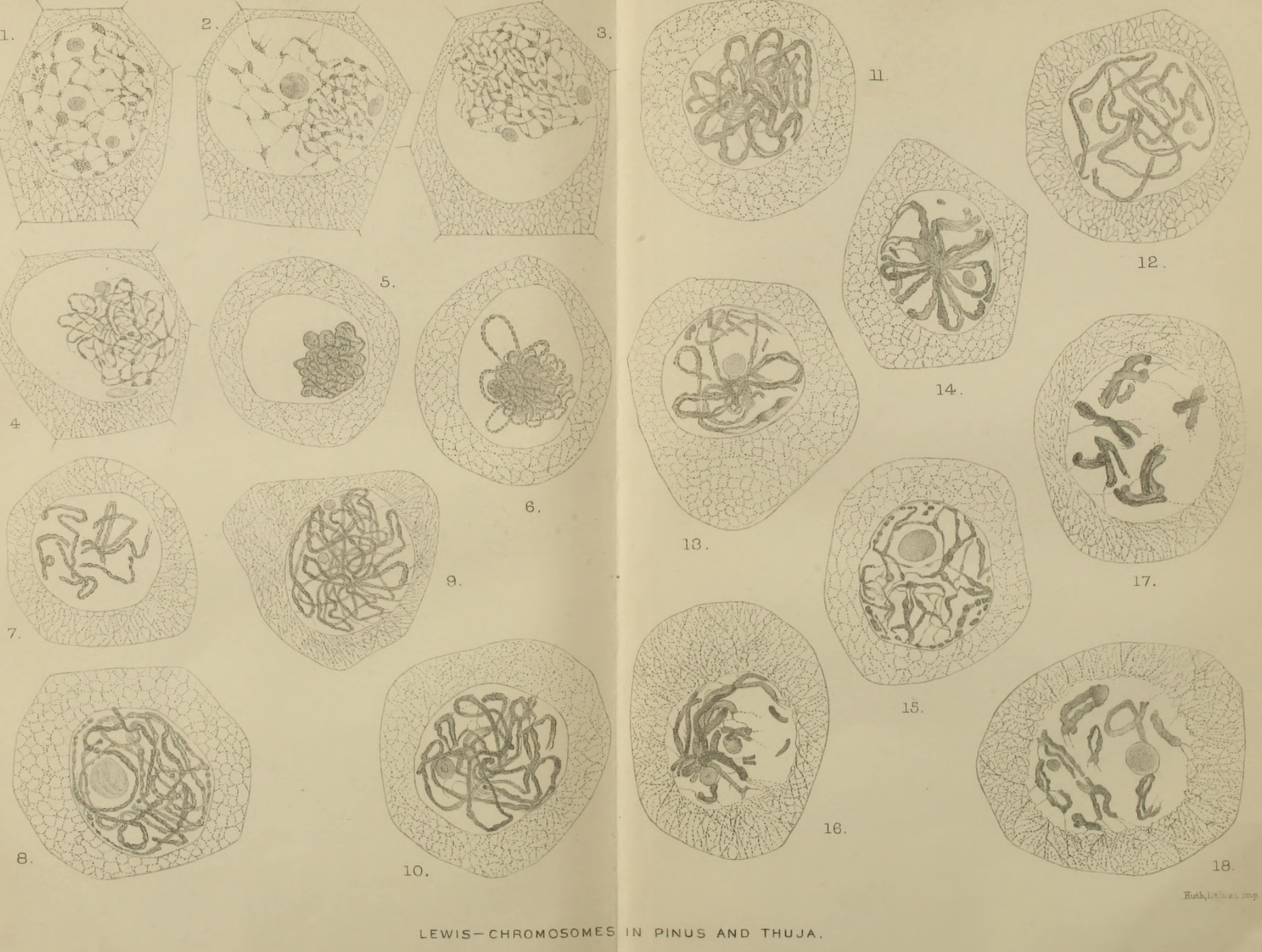


Annals of Botany,

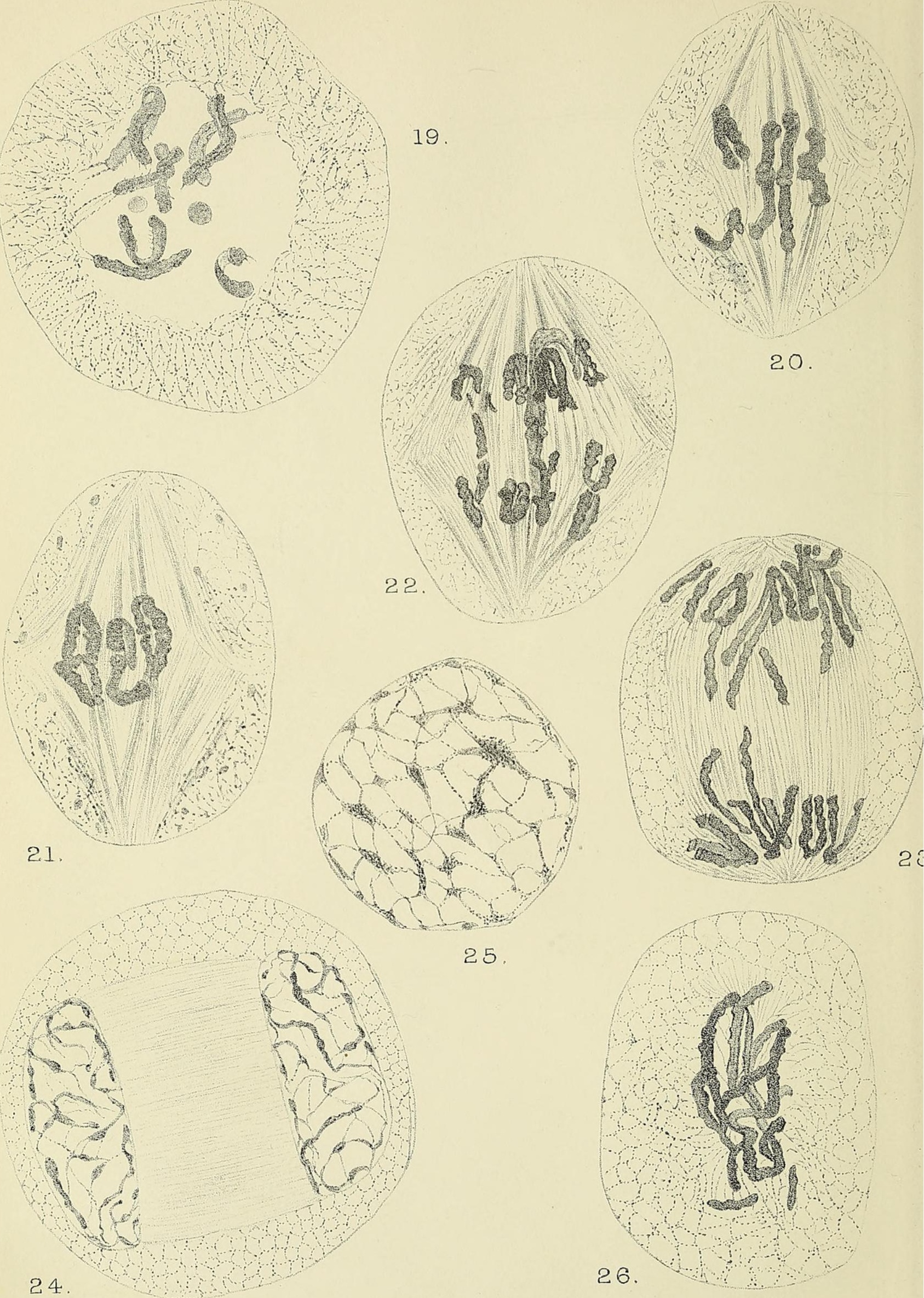


(i)

12

27.
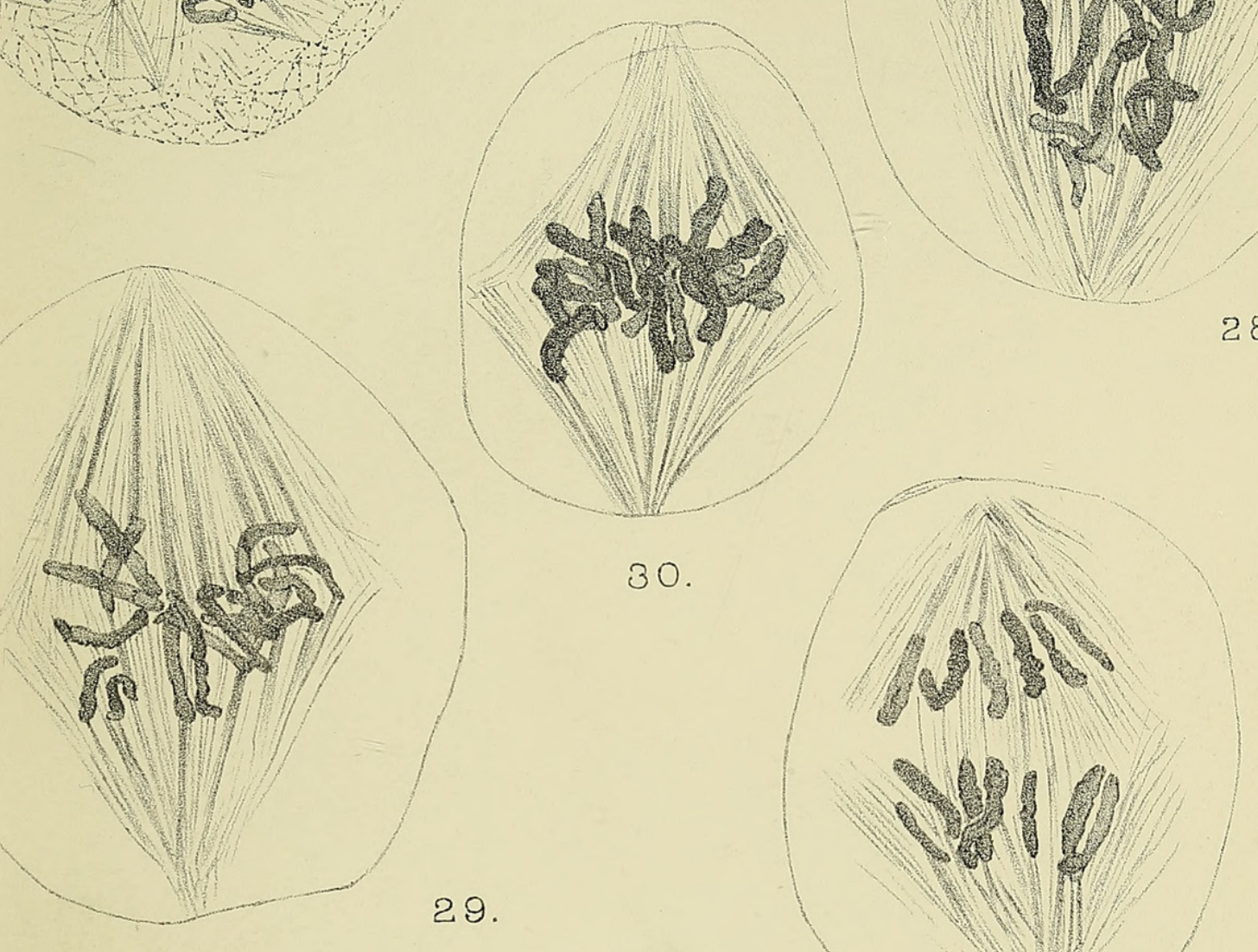

28.

32.
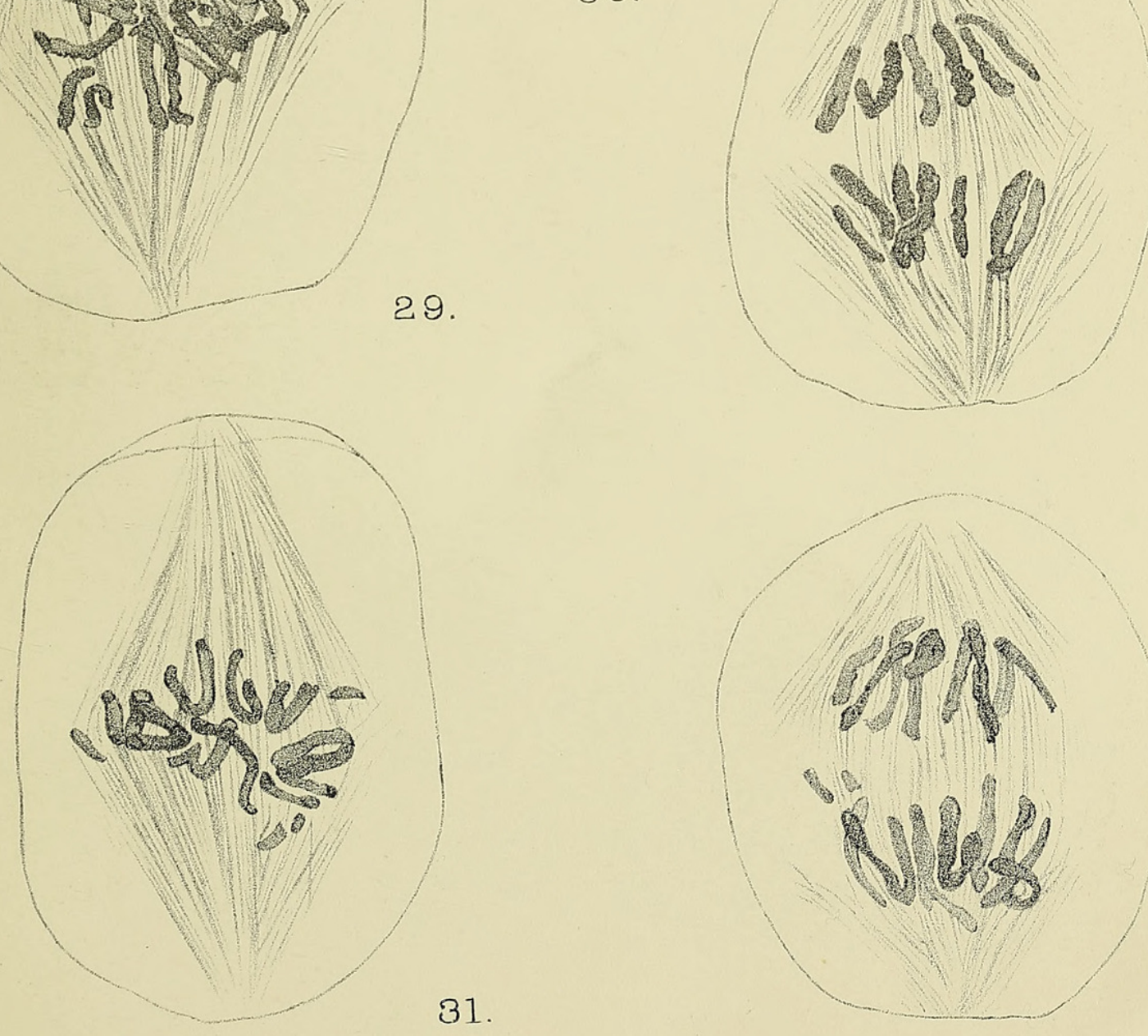

31.

33. 

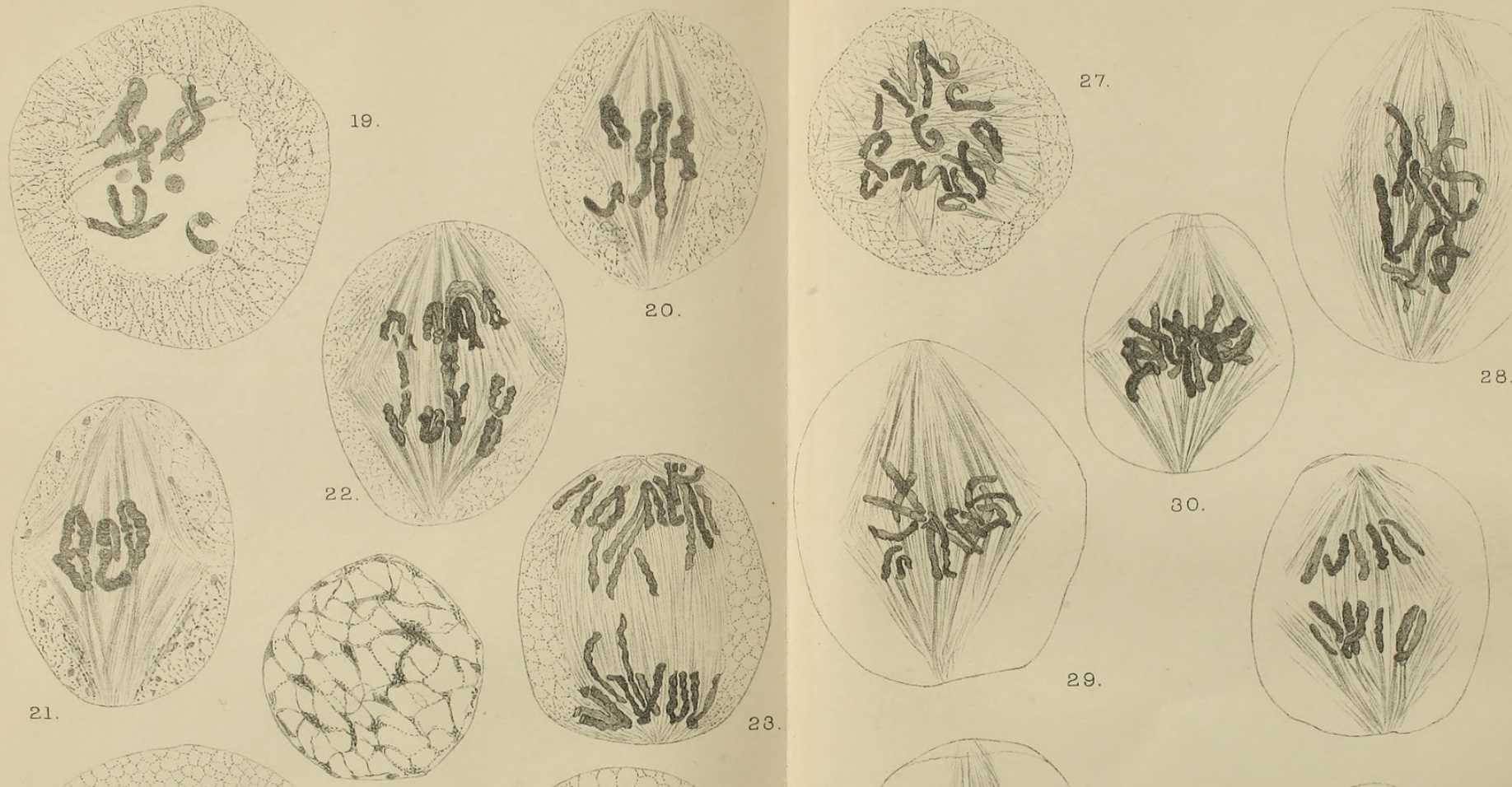

28.
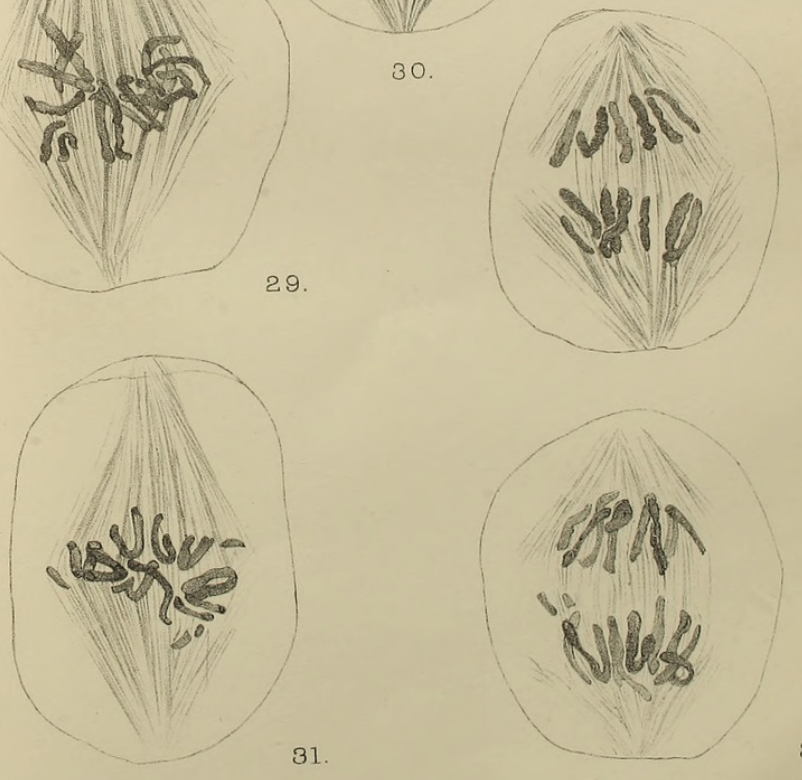

31. 


\section{$2 \mathrm{BHL}$ Biodiversity Heritage Library}

Lewis, I M. 1908. "The behaviour of the chromosomes in Pinus and Thuja." Annals of botany 22, 529-556.

https://doi.org/10.1093/oxfordjournals.aob.a089189.

View This Item Online: https://www.biodiversitylibrary.org/item/232525

DOI: https://doi.org/10.1093/oxfordjournals.aob.a089189

Permalink: https://www.biodiversitylibrary.org/partpdf/318925

\section{Holding Institution}

Smithsonian Libraries

\section{Sponsored by}

Biodiversity Heritage Library

\section{Copyright \& Reuse}

Copyright Status: Not in copyright. The BHL knows of no copyright restrictions on this item.

This document was created from content at the Biodiversity Heritage Library, the world's largest open access digital library for biodiversity literature and archives. Visit BHL at https://www.biodiversitylibrary.org. 